\title{
On the Status of Mute Letters in French : Simple Graphemes or Part of Complex Graphemes?
}

Carine Royer, Elsa Spinelli and Ludovic Ferrand

\section{(2) OpenEdition}

Electronic version

URL: http://journals.openedition.org/cpl/465

DOI: $10.4000 / \mathrm{cpl} .465$

ISSN: $1379-6100$

Publisher

Centre PsyCLÉ

\section{Electronic reference}

Carine Royer, Elsa Spinelli and Ludovic Ferrand, «On the Status of Mute Letters in French : Simple Graphemes or Part of Complex Graphemes ? », Current psychology letters [Online], 16, Vol. 2, 2005 | 2005, Online since 09 May 2005, connection on 08 September 2020. URL : http:// journals.openedition.org/cpl/465; DOI : https://doi.org/10.4000/cpl.465

This text was automatically generated on 8 September 2020

(c) All rights reserved 


\title{
On the Status of Mute Letters in French : Simple Graphemes or Part of Complex Graphemes?
}

\author{
Carine Royer, Elsa Spinelli and Ludovic Ferrand
}

Received October 10, 2004

Revised March 3, 2005

Accepted April 25, 2005

On line May 9, 2005

Graphemes are commonly defined as the written representation of phonemes (Coltheart, 1978; Henderson, 1985). For example, the word char /S/ in French is composed of four letters (C,H,A, and R) but only three graphemes ( $\mathrm{CH}$ corresponding to the phoneme /S/, A and R corresponding to the phonemes / $\mathrm{a} /$ and // respectively). On the contrary, there is a direct match between letters and graphemes in the French word tuba // ( $/ \mathrm{t} /, \mathrm{U} / \mathrm{y} /, \mathrm{B} / \mathrm{b} /, \mathrm{A} / \mathrm{a} /)$. Hence, one letter can either correspond to a simple grapheme (single letter grapheme) such as A in char or tuba or be part of a complex grapheme -i.e. embedded in a multi-letters grapheme- such as A in the French word Pause //.

An important debate in the field of written word recognition concerns the processes underlying the mapping of the sensory information from the visual input to the stored entries in the lexicon. More precisely, a central question is to determine which abstract components such as features, letters, graphemes or syllables are involved in the process of contacting the lexicon. Contrary to letter units, grapheme units allow a more direct correspondence between orthographic and phonological word forms. Hence, graphemes have recently been proposed as functional units to mediate access to the lexicon.

Recent studies have shown penalties in the processing of words and non words with letter/grapheme units mismatch compared to stimuli composed of simple graphemes. Rastle and Coltheart (1998) compared naming latencies to five letters long non words differing in terms of number of graphemes (e.g. FOOFH /fuf/ : 3 graphemes and FROLP 
/frolp/: 5 graphemes). Naming latencies were shorter for the stimuli showing no mismatch between letters and graphemes, i.e. when non words contained as many graphemes as letters (FROLP). In a similar vein, Rey, Jacobs, Schmidt-Weigand and Ziegler (1998) found in a perceptual identification task that response times were shorter for words containing as many graphemes as letters (BLAST: 5 graphemes) compared to words with fewer graphemes than letters (TEETH : 3 graphemes). Taken together, these two studies show that manipulating the number of graphemes affect performances in reading and suggest that during the reading process, there is a stage of clustering letters into bigger grapheme units. Recently, Rey, Ziegler and Jacobs (2000) showed with a letter-detection task in French and English that graphemes are processed as perceptual units by the reading system. Target letters could either be single-letter grapheme (e.g. subjects had to detect A in place, /las/) or part of a multiletters grapheme (e.g. they had to detect A in pause, //). Rey et al. (2000) found shorter response times for single-letter graphemes than for multi-letter grapheme, suggesting that graphemes are functional units in reading. Moreover, they showed that this effect was not contaminated by the phonemic realisation of the target letter.

Hence, recent studies suggest that letters are combined into grapheme units that could serve to mediate lexical access. This stage seems straightforward for the reading system for all letters that have a phonemic realisation whether they are single-letter graphemes (e.g. in place, letter a grapheme A) or multi-letters graphemes (e.g. in pause, letters a + ugrapheme AU). However, because graphemes are defined as the written representation of phonemes it remains to be seen how the system deals with letters that are not pronounced. Lee and Turvey (2003) examined the impact of deleting a silent letter (e.g. " $p$ " in PSALM) on the activation of the word PSALM. In naming and lexical decision tasks associated to a masked priming paradigm, they found a facilitatory effect for salm-PSALM compared to a control condition suggesting that phonological information provided by the pseudohomophone allowed activation of the target word. However, they also found a penalty for salm-PSALM compared to an identity condition which suggests that the activation of the target word nevertheless suffers from deletion of a silent letter. The authors argue that the phoneme /s/ is connected to both the single letter $\mathrm{S}$ and the grouping of letters PS.

Considering the French word chat composed of four letters (C,H,A, and T) but only two

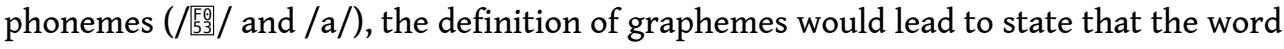
chat has two multi-letters graphemes $(\mathrm{CH}+\mathrm{AT})$. Alternatively, one might consider that the two letters $a$ and $t$ are not bound together to form a complex grapheme but are two single-letters graphemes. The mute letter $t$ in chat would then have one single grapheme representation, corresponding to no phoneme (i.e. it could be a "mute grapheme"). The aim of this study is to evaluate the status of mute letters in French and to tease apart whether mute letters are bound to the preceding vowel to form a complex grapheme or whether they are simple graphemes. Given the results of Rey et al. (2000) -who found shorter responses times for simple graphemes than for multiletters graphemes-, if mute letters correspond to simple graphemes, subjects should detect faster a target letter (e.g. A) when associated to a mute letter (e.g. in CHAT) than when it is part of a multi-letters grapheme (e.g. in QUAI). Alternatively, if AT in CHAT constitutes a multi-letters grapheme, subjects should detect slowlier the target letter A in CHAT than in CHAR (in which it corresponds to a simple grapheme).

ExperimentParticipants 
Nineteen students of the University Pierre Mendès France, Grenoble, participated in the experiment for course credit. All participants were native speakers of French and had normal or corrected vision.

Stimuli

The stimulus set was composed of 123 target-present trials (i.e. the target letter was in the word) and 123 target-absent trials.

Target-present trials: Forty-one triplets of words were selected from the French data base "Lexique" (New, Pallier, Ferrand \& Matos, 2001) corresponding to three conditions : in a first condition, the target vowel (e.g. A) was associated to a mute letter (e. g. A in CHAT - / Sa /: mute condition), in a second condition, the target vowel corresponded to a single-letter grapheme (e. g. A in CHAR - / /: single-letter grapheme condition), and in a third condition the target vowel was embedded in a multi-letters grapheme (e. g. A in QUAI - / /: multi-letters grapheme condition). The 41 triplets were individually matched in Frequency (31 occurrences per million for the mute condition, 16 occurrences per million for the simple grapheme condition and 37 occurrences per million for the multi-letters grapheme condition), in number of letters (4.8 in each condition) and in number of syllables (1.6 in each condition). The triplets were also matched for position of the target letter in the word. The mute and multi-letters grapheme conditions were matched in number of phonemes (3.4 in each condition) but the simple grapheme condition was systematically one phoneme longer (4.4 phonemes on average). Three types of targets were chosen: I consisting of 15 triplets (e.g. tapis //, actif - //, lapin - )/, $U$ consisting of 10 triplets (salut - //, virus - //, odeur - //) and $A$ consisting of 16 triplets (CHAT - / /, CHAR - / /, QUAI - / /).

Target-absent trials: Forty-eight words were associated to the target vowel A: 24 words did not contain the target vowel A nor the other targets I or $U$ (e.g. ROCHE -//, absence condition) and 24 words did not contain the target vowel $A$ but at least one of the other targets I and/or U (e.g. BRUIT - //, catch trials condition). Thirty words were associated to the target vowel $U, 15$ words in the absence condition (e.g. BLOND - /)/) and 15 words in the catch trials condition (e.g. GAZON - /)/). Forty-five words were associated to the target vowel $I, 22$ words in the absence condition (e.g. NORME - //) and 23 words in the catch trials condition (e.g. AMOUR - //). Both conditions (absence and catch trials) were matched in frequency (37.6 and 36.2 occurrences per million respectively), number of phonemes (3.6 in both conditions), number syllables (1.4 and 1.55 respectively), and number of letters ( 4.75 and 4.77 respectively).

Procedure

The procedure was that used by Rey et al. (2000). Participants were tested individually in a quiet room. Each trial began with a $700 \mathrm{~ms}$ presentation of a target letter in the center of a computer screen (e.g. A). Then a fixation mark (:) was presented for $1000 \mathrm{~ms}$ and was replaced by a stimulus word (e.g. chat), which remained on the screen for 33 ms; the stimulus word was followed by a blank interval of $70 \mathrm{~ms}$. Then a mask (\#\#\#\#\#) appeared and remained on the screen until participants responded. Participants had to decide as accurately and as quickly as possible whether the target letter was in the stimulus word or not by using one of the two response buttons. Participants were required to press the "yes" button with the forefinger of their preferred hand. The target letter was presented in uppercase and the stimulus word in lowercase. The experiment was controlled by E-prime. The computer clock was triggered by the presentation of the mask on the screen and stopped by the subjects' response. Response 
latencies and errors were collected. The session began by 30 practice trials. Then the 246 trials (123 target present and 123 target absent) were presented in a randomized order for each participant. The experimental factor : graphemic status (mute, singleletter grapheme, multi-letters grapheme) was a within subjects factor. The session lasted approximately twenty minutes.

Results

Mean Reaction Times (RT), Standard Deviation (SD) and Error rates for the target vowels presented in the three conditions are presented in Table 1. Incorrect responses (5.3\% of responses), and RTs longer than $1500 \mathrm{~ms}$ and shorter to $200 \mathrm{~ms}$ (1.7\%) were removed. The results were evaluated using one-way Anovas with three levels of condition (mute condition, single-letter grapheme condition, multi-letters grapheme condition). $F$ values are reported by subjects $\left(F_{1}\right)$ and by items $\left(F_{2)}\right.$ and all significance tests have

Table 1: Mean Reaction Times in Milliseconds (RT), Standard Deviation (SD) for correct responses to the targets and Error rates in the three conditions.

\begin{tabular}{llll}
\hline & Mute & $\begin{array}{l}\text { Single-letter } \\
\text { grapheme }\end{array}$ & $\begin{array}{l}\text { Multi-letters } \\
\text { grapheme }\end{array}$ \\
\hline RT (ms) & & & \\
SD & 476 & 485 & 512 \\
Error rates(\%) & $(56)$ & $(64)$ & $(58)$ \\
& 5.3 & 4.9 & 5.9 \\
\hline
\end{tabular}

Analyses of RTs revealed a main effect of the graphemic status significant both by subjects and by items $(F 1(2,36)=12.94, p<.001, \quad F 2(2,80)=8.85, p<.001)$. Planned comparisons showed shorter responses times for the single-letter grapheme condition compared to the multi-letters grapheme condition $(F 1(1,18)=21.3, p<.001, F 2(1,40)=7.65$, $p<.001)$. Moreover, the analyses showed shorter responses times for the mute condition compared to the multi-letters grapheme condition $(F 1(1,18)=26.87, \quad p<.001$, $F 2(1,40)=15.25, p<.001)$. The mute condition did not differ with the single-letter grapheme condition $(F 1(1,18)=1.21$, ns, $F 2(1,40)=1.39$, ns). Analyses conducted on errors showed no difference between the three conditions (All Fs $<1$ ).

Discussion

Our results showed that a target letter is harder to detect when it is part of a multiletters grapheme (e.g. A in QUAI) than when it consisted of a single-letter letter grapheme (e.g. A in CHAR). This result replicated that of Rey et al. (2000) who found that both English and French subjects took longer to detect a target letter in a word when this letter was embedded in a multi-letters grapheme than when it corresponded to a single-letter grapheme. Crucial to our purposes, we found that subjects detected faster letters associated to mute ones than letters corresponding to multi-letter graphemes. This suggests that mute letters are not bound to their preceding vowel to form multiletters graphemes. On the contrary, it seems that mute letters correspond to singleletter graphemes.

Before turning into the implications of our results, it should be noted that there is a confound between the graphemic status and the phonemic realisation of the vowel. $A$ is 
realized as the name of the letter $(/ \mathrm{a} /)$ both in CHAT and CHAR but is realized differently (/E/) in QUAI. This problem is unsolvable in French since the pronunciation of letters embedded in multi-letters graphemes is always changed. In English however, it is possible to disentangle the two factors. Rey et al. (2000) did so and replicated their results keeping the phonology constant. They found shorter response times to detect $\mathrm{O}$ in SLOPE (single-letter grapheme) than in FLOAT (multi-letters grapheme). Moreover, they found no interaction with phonology when it was manipulated. Hence, although there is no way to directly control for such a phonological confound in French, it should be surprising that a particular effect would be insensitive to phonology in English and attributed entirely to phonology in French. Nevertheless, there is abundant evidence for an automatic activation of the phonological code during silent reading (Ferrand \& Grainger, 1992, 1993) and one cannot exclude that incongruency between letters' orthography and phonology could slower the responses.

Providing that the difference between the mute-letter condition and the multi-letter condition is not (or entirely not) due to activation of the letter's name, our results suggest that in French, simple graphemes could represent mute letters, which means that graphemes are not strictly speaking, the written representation of phonemes. A word like CHAT would then have three graphemes, the last one being a mute grapheme, hence standing for no phoneme. Why would the reading system consider such mute graphemes separately instead of binding them to the preceding vowel to form a complex grapheme, since they have no phonological function?

On the one hand, a possible explanation of the segmentation of mute grapheme would be that units formed by a vowel + a mute letters like AT are inconsistent orthophonological units. Contrary to complex graphemes (like AI, that is almost systematically associated to the phoneme //), the letter sequence $A T$ can be associated with either one phoneme (e.g. /a/) in CHAT or two phonemes (e.g. /at/) in the morphologically complex word derived from chat e.g. chaton //. Hence, it could be that sequences of letters that can be associated to either one or more than one phonemes (such as $A T$ ) would be less cohesive units than sequences of letters that are always associated to only one phoneme (like $A I$ ). If this is the case, one might predict that although both sequences of letters like $A I$ and $A N$ are complex graphemes, $A I$ would be more of a cohesive unit that $A N$ given that $A N$ can be realised either // (e.g. in CRAN, // or // (e.g. in CRANE, /n/).

On the other hand, we could explain the segmentation of mute graphemes considering that they have a special function and/or status during reading: a morphological function (Catach, 1995). Although the final $t$ in CHAT is not phonemically realized, it is pronounced in morphological complex words derived from chat e.g. chaton //, chatte //, chattière // etc. Hence, the final $t$ in chat could stand for the morphological productivity of the word. As functional reading units, it could be hypothesized that graphemes would not only serve the mapping onto phonology but also onto morphology. If this is the case, we should predict a difference in the processing of mute letters whether they constitute a morphogram (e.g. such as $T$ in CHAT or $S$ in TAPIS //) or not (e.g. such as $S$ in RADIS //).

Further research is needed to examine why mute letters are considered as simple graphemes by the reading system and to disantangle a phonological explanation from a morphological one. 


\section{BIBLIOGRAPHY}

Appendix

Catach, N. (1995). L'orthographe Française. Paris : Nathan Université.

Coltheart, M. (1978). Lexical access in simple reading tasks. In G. Underwood, Strategies of information processing, London: Academic Press.

Ferrand, L., \& Grainger, J. (1992). Phonology and orthography in visual word recognition: Evidence from masked nonword priming. Quarterly Journal of Experimental Psychology, 45, 353-372.

Ferrand, L., \& Grainger, J. (1993). The time course of orthographic and phonological code activation in the early phases of visual word recognition. Bulletin of the Psychonomic Society, 31, 119-122.

Henderson, L. (1985). On the use of the term "grapheme". Language and Cognitive Processes, 2, 135-148.

Lee, C. H.\& Turvey, M. T. (2003). Silent Letters and Phonological Priming. Journal of Psycholinguistic Research, 32, 313-333.

New B., Pallier C., Ferrand L., \& Matos R. (2001) Lexique : Une base de données lexicales du français contemporain sur internet. L'Année Psychologique, 101, 447-462.

Rastle, K \& Coltheart, M. (1998). Whammy and double whammy: Length effects in nonword naming. Psychonomic Bulletin and Review, 5, 277-282.

Rey, A., Jacobs, A. M., Schimdt-Weigand, F., \& Ziegler, J. C (1998). A phoneme effect in visual word recognition. Cognition, 68 , 41-50.

Rey, A., Ziegler, J. C, \& Jacobs, A. M. (2000). Graphemes are perceptual reading units. Cognition, 75, B1-B12.

\section{ABSTRACTS}

Recent studies have suggested that letters are combined into grapheme units that could serve to mediate lexical access. The aim of this study is to evaluate the status of mute letters in French and to assess whether mute letters are simple graphemes or part of complex graphemes. In a letter-detection task, we found that a target letter is harder to detect when it is part of a multiletters grapheme (e.g. A in QUAI [kE]) than when it consisted of a single-letter letter grapheme (e.g. A in CHAR [Sa圈]), thus replicating Rey et al. (2000)'s results. We also found that subjects detected the target letter A faster in CHAT [Sa] (in which it is associated to a mute letter) than in QUAI (in which it is part of a complex grapheme). This suggests that mute letters correspond to simple graphemes and that they are not bound to their preceding vowel to form complex graphemes.

L'objectif de cette recherche est d'évaluer le statut des lettres muettes et, plus précisément, de savoir si elles constituent des graphèmes simples ou si elles font partie d'un graphème complexe en étant associées à la voyelle qui les suit ou précède. Avec une tâche de détection de lettre, nous avons montré que les voyelles (ex « $\mathrm{A} »)$ sont détectées plus rapidement lorsqu'elles correspondent à un graphème simple (ex : dans "CHAR») que lorsqu'elles font partie d'un graphème complexe (ex : dans QUAI), ce qui réplique les résultats de Rey et al. (2000). Par ailleurs, 
les voyelles $(\mathrm{ex}$ « $\mathrm{A} »)$ sont détectées plus rapidement lorsqu'elles sont accolées à une lettre muette (ex : dans «CHAT») que lorsqu'elles correspondent à un graphème complexe (ex : dans "QUAI »). Ceci suggère que les lettres muettes sont traitées comme des graphèmes simples et qu'elles ne sont pas associées à la voyelle qui les suit ou précède pour former un graphème complexe.

INDEX

Keywords: graphemes, mute letters, letter-detection task

\section{AUTHORS}

\section{CARINE ROYER}

Laboratoire de Psychologie et NeuroCognition Université Pierre Mendès France, Grenoble, France

\section{ELSA SPINELLI}

Laboratoire de Psychologie et NeuroCognition Université Pierre Mendès France, Bâtiment Sciences de l'Homme \& Mathématiques BP 4738040 Grenoble Cedex 9, France elsa.spinelli@upmf-grenoble.fr

\section{LUDOVIC FERRAND}

CNRS, Université René Descartes, Paris 5, France 